\title{
Relationship between pharmaceutical pricing strategies with price, availability, and affordability of cardiovascular disease medicines: surveys in Qatar and Lebanon
}

\author{
N. Abdel Rida', M. I. Mohamed Ibrahim" ${ }^{1 *}$ and Z. U. D. Babar ${ }^{2}$
}

\begin{abstract}
Background: Cardiovascular diseases are the leading cause of death in Lebanon and Qatar. When lifestyle modifications prove insufficient, medication becomes a cornerstone in controlling such diseases and saving lives. Price, availability, and affordability hinder the equitable access to medicines. The study aimed to assess prices, availability, and affordability of essential cardiovascular disease medicines in relation to pricing strategies in Qatar and Lebanon.
\end{abstract}

Methods: A cross-sectional survey using a variant of the World Health Organization and Health Action International (WHO/HAl) methodology as outlined in "Measuring medicine prices, availability, affordability and price components" (2008), second edition, was adopted. Prices and availability of 27 cardiovascular medicines were collected from public and private dispensing outlets. For international comparison, prices were adjusted to purchasing power parity. Data was analyzed across multiple sectors, within and across countries.

Results: A total of 15 public and private outlets were surveyed in each country. Prices were more uniform in Qatar than in Lebanon. In the public sector, medicines were free-of-charge in Lebanon and priced lower than the international reference prices in Qatar. The ratio of medicine unit price to international reference price in the private sectors surveyed are significantly higher than the acceptable threshold of 4 . This ratio of originator brands and lowest priced generics in Qatar were up to two and five times those in Lebanon, respectively, even after adjusting for purchasing power parity. However, prices of lowest priced generics in the private sector were at least 35\% cheaper in Qatar and 65\% cheaper in Lebanon than their comparative originator brands. Medicines were more available in the private sector in Lebanon than in Qatar, but only the originator brand availability in the public sector in Qatar exceeded the WHO target of more than $80 \%$. While affordable in the public sector in Qatar, four out of thirteen medicines exceeded the threshold in all private sectors covered. Hence, only the public sector in Qatar had a satisfying level of availability and affordability.

Conclusions: Except for the Qatari public sector, medicine prices, availability, and affordability are falling short from targets. Key policy decisions should be implemented to improve access to medicines.

Keywords: Cardiovascular disease, Medicine access, Medicine policy, Generic medicine, Medicines prices

\footnotetext{
* Correspondence: mohamedizham@qu.edu.qa

${ }^{1}$ College of Pharmacy, Qatar University, PO BOX 2713, Doha, Qatar

Full list of author information is available at the end of the article
}

(c) The Author(s). 2019 Open Access This article is distributed under the terms of the Creative Commons Attribution 4.0 International License (http://creativecommons.org/licenses/by/4.0/), which permits unrestricted use, distribution, and reproduction in any medium, provided you give appropriate credit to the original author(s) and the source, provide a link to the Creative Commons license, and indicate if changes were made. The Creative Commons Public Domain Dedication waiver (http://creativecommons.org/publicdomain/zero/1.0/) applies to the data made available in this article, unless otherwise stated. 


\section{Background}

Medication is a cornerstone in medical disease management and the timely presence and appropriate integration of medication in a treatment plan for short- and long-term ailments are crucial. This is quite evident in the life-long treatment of non-communicable diseases (NCD) such as cardiovascular diseases (CVD) when first-line lifestyle modifications [1-3] are proven inappropriate and unsuccessful. According to the latest WHO global disease burden report (2014), NCD are the leading cause of death worldwide of which CVD accounted for almost half of the death cases. Similar high figures were observed in the Eastern Mediterranean Regional Office of the WHO (EMRO) [4] as well where risk factors for CVD and non-adherence to primary management guidelines are highly prevalent [5-7].

Therefore, ensuring a sustainable access to medicines is deemed indispensable. Access can be defined by the ability of citizens to reach and use pharmaceuticals that are of good quality and affordable, when needed [8]. The price of medicines was one of the barriers to such consistent access [9]. Furthermore, data from few smallscale studies had shown that prices in low-income countries were higher than in richer countries. Several nongovernmental organizations (NGO) and WHO acknowledge that to improve the availability and the affordability of essential medicines, evidence-based national policies and programs must be developed. Sound information based on systematic surveys of standard methodology to evaluate the price and availability of medicines was lacking. As a result, the WHO/HAI Project on Medicine Prices and Availability was established in 2001. After several provisional surveys, the methodology was launched in 2003, and has since been regularly reviewed to increase its efficiency and transparency [9]. Several middle-eastern countries, e.g., Kuwait, Lebanon, and Syria, participated in the first version of WHO/HAI project in 2003, and consequently undertook action towards medicine price reduction and enhancement of availability based on the survey findings and recommendations [10]. A closer look into two middle-eastern countries within the EMRO, Qatar and Lebanon, of different economic indicators demonstrated that cardiovascular diseases are the first leading causes of death in Lebanon and the second in Qatar after road injuries [11]. Both countries included prevention strategies against chronic diseases generally and CVD especially in their national vision and had set future plans to manage and control the spread of cardiovascular diseases [1214]. Moreover, the medicine prices were perceived to be high in these two countries compared to respective neighboring countries [15-17]. Considering this evidence, Abdel Rida et al. conducted a narrative review and document analysis of the pharmaceutical pricing policies in Qatar and Lebanon [18]. Both Qatar and Lebanon have implemented similar pharmaceutical pricing policies. External reference pricing (ERP) is one of the pricing policies adopted by both countries, albeit with different baskets of reference countries. The basket of countries to which the prices in each country are benchmarked vary $[19,20]$. In addition to ERP, mark-up regulations are applied with different schemes along the pharmaceutical supply chain. While a decree detailing all the different regressive mark-up ${ }^{1}$ schemes is available to the public in Lebanon [21], such detailed scheme is not available in Qatar. The standardized mark-up is linear and capped at $44 \%$ on all medicine in the private sector. In addition, Qatar may consider the economic evaluation of a medicine to set the price if such evaluation or Health Technology Assessment (HTA) is available at the time of registration [20]. The prices of generic medicines are set at fixed lower percentage in comparison to the price of the originator brand in both countries as per Appendix. Generic brands are classified according to the chronological order in which they get registered and enter the market in both Qatar and Lebanon $[19,20]$. The price of the first registered generics is 30 and $35 \%$ lower than their comparative $\mathrm{OB}$ available in the market in Lebanon and Qatar respectively. Additionally, pricing of generics in Lebanon considers the country of origin in a pricing strategy and the price variation of different generic brands within the same category similar to internal reference pricing used internationally $[19,22]$. Lebanon also adopts yet a different markup scheme for locally manufactured generics [19].

Qatar and Lebanon differ in terms of economic indicators due to the differences in income levels. While Qatar is a high-income country, Lebanon is an upper-middle income country. The pharmaceutical sector is a major subset of the health sector especially with spending on pharmaceuticals constituting a high percentage of the total health expenditure [23-25]. In Lebanon, almost half of the health expenditure is attributed to purchase of pharmaceuticals [26] while it only constitutes $10.90 \%$ of the total health expenditure in Qatar where most of the expenditure on health was in the public sector as per Table 1 below. In the last decade, the public health sector in Qatar has been expanding to provide highstandard primary health care services across the state. The health services are provided for free for Qatari citizens while residents or non-Qatari pay $20 \%$ of the total healthcare bill. The primary health care centers in Lebanon cover most of the Lebanese territory, however,

\footnotetext{
${ }^{1}$ Mark-up: The additional costs to the manufacturer selling price (MSP) in the form of charges and costs to cover different stages of the distribution chain including profits, overheads cost, and distribution fees. Regressive mark-up: lower mark-up for higher priced medicines.
} 
Table 1 Qatar and Lebanon economic indicators and demographics

\begin{tabular}{lll}
\hline & Qatar & Lebanon \\
\hline GDP (bn) & $\$ 164.64$ & $\$ 47.08$ \\
Population (mn) & $2.58^{\mathrm{a}}$ & $6.24^{\mathrm{b}}$ \\
$\quad$ Citizens (mn) & $0.313^{\mathrm{c}}$ & $4.757^{\mathrm{b}}$ \\
GDP Per Capita (35) & $\$ 73,653$ & $\$ 8,047$ \\
Health Expenditure (bn) & $\$ 4.82$ & $\$ 3.34$ \\
$\quad$ Public Health Expenditure (bn) & $\$ 4.10$ & $\$ 1.59$ \\
$\quad$ Private Health Expenditure (bn) & $\$ 0.72$ & $\$ 1.75$ \\
Pharmaceutical Sales (bn) & $\$ 0.52$ & $\$ 1.64$ \\
Pharmaceutical Sales, \% of Health Expenditure & 10.90 & 49.00 \\
Per Capita Spending on Pharmaceuticals & $\$ 234$ & $\$ 280$ \\
Spending on Originator Pharmaceuticals (mn) & $\$ 360.0$ & $\$ 800.0$ \\
Spending on Generic Pharmaceuticals (mn) & $\$ 110.0$ & $\$ 490.0$ \\
\hline
\end{tabular}

Source:

World Bank [27]

Business Monitor International (BMI) [26]

Business Monitor International [28]

a Ministry of Development Planning and Statistics (mdps) [29]

${ }^{\mathrm{b}}$ Central Intelligence Agency (CIA) [30]

'Snoj [31]

due to budget constraints, services are limited in terms of population coverage, clinical services and pharmaceutical products dispensing. If available, medicines are dispensed free of charge for beneficiaries in the public primary health centers in Lebanon. Out of an approximate population of 4.5 million in 2011, only 162,016 patients had access to chronic non-communicable diseases medicines from the public sector in Lebanon [17].

The management and control of the spread of CVD starts with a prevention plan, however, treatment is equally essential. While acknowledging the efforts of both countries to implement pricing guideline (e.g., benchmarking and mark-up), it is imperative to analyze the status of essential medicines (i.e. the access to essential medicines in terms of price, availability, affordability, and accessibility) aimed at treating CVD which are highly prevalent. Assessing access to these medicines is needed in order to achieve optimal adherence to secondary prevention measures in treating early stages of CVD, to minimize complications, hospitalizations, and mortality, and to control the total cost of diseases management [23]. Level of access to medication is determined through the evaluation of prices, availability and affordability of these medicines [32]. Thus far no research has been conducted in Qatar to investigate whether all essential CVD medicines are available or affordable in the private or public sector especially after the phased price cut undertaken by the gulf countries [33]. In this phased price cut, medicines were classified into five main categories and the prices within each category were reviewed and reduced [33]. Similarly, the latest survey conducted in Lebanon by the WHO/HAI included only three CVD medicines [17] and was published in 2013 prior to the latest review of pharmaceutical pricing guidelines at the end of 2014 [21]. The main objective of the WHO/HAI survey is to collect reliable data related to prices, availability, and affordability of a specific basket of medicines and price components added throughout the supply chain. Given the profile of CVD and the pharmaceutical pricing containment strategies undertaken in Qatar and Lebanon as presented above [19-21], this study was developed to collect data from different sectors and medicine selling outlets (i.e. community pharmacies or outpatient pharmacies), in order to permit a better understanding of the current pharmaceutical situation in terms of cardiovascular disease medicines price, availability, and affordability in both countries.

\section{Methods}

Study methodology overview

Ideally, WHO/HAI methodology is used for a national survey, or across a state or province in case of large countries. Data about the medicines' price, availability and affordability are collected from up to 4 different sectors. It is recommended to cover at least the capital plus 5 other areas within one-day drive from the capital. In each area, it is recommended to collect data from 5 outlets per sector. In case of an outlet with an availability of medicines less than $50 \%$ of the list surveyed, another outlet within the same area should be visited. Moreover, validation visits for $20 \%$ of the outlets is recommended. Lebanon and Qatar have comparable areas, $10,452 \mathrm{~km}^{2}$ and $11,610 \mathrm{~km}^{2,}$ respectively [34]. However, the populations vary significantly. Lebanon has a population of more than 5 million, almost double the population of Qatar with a much higher population density [34]. According to WHO/HAI [9], the selection of the covered areas should be based on geographical districts around the country with a minimum population density. The real retail price paid by the patient is collected in each sector in local currency. Surveyed outlets should have an outpatient pharmacy dispensing medicines directly to the patient. To calculate the affordability, the lowestpaid unskilled government worker (LPGW) salary is identified. Affordability is then estimated based the cost of a full treatment regimen for either acute or chronic disease in terms of the number of the days' wages forgone by the LPGW to purchase the treatment. The outlet sampling is conducted in a randomized and systematic manner to ensure enough coverage. The selection of outlets is related to the demographics of a given area surveyed. The purpose is to randomly choose a region and consequently outlets that comply with the criteria set by WHO/HAI e.g.: minimum population and 
distance from the capital. The list of surveyed medicines can include up to 50 medicines while the affordability can be calculated for up to 22. For each medicine, data about the originator brand (OB) and lowest-priced generic (LPG) available at the outlet are collected. The second edition of Measuring medicine prices, availability, affordability, and price components (2008) of WHO/HAI methodology was adopted with some variations in terms of number of areas covered in Qatar; facility number per sector and area; back-up and validation visits. This was due to the inherent geographical and demographic characteristics of the countries surveyed as mentioned above especially in Qatar and to the limited resources available to the researchers.

\section{Study design}

The study was a cross-sectional observational and comparative survey, carried out in two different countries: Qatar and Lebanon. The main areas surveyed were the capital cities in both countries (Doha and Beirut) in addition to other administrative areas within one-hour drive from each capital. In Lebanon, the population is dispersed across the country. However, Qatar has a centralized population density around fewer main cities or municipalities. As such, the availability and types of healthcare services and facilities in both countries are reflective of the demographic profiles. The $1+5$ target was achievable in Lebanon due to its multiple population centers [9]. However, the centralized population in Qatar limited our surveyed areas to $1+4$.

\section{Population sampling and data collection}

Data were collected from public health care centers (Public Sector), private pharmacies (Private Sector) in both countries and private hospitals or clinics (Other Sector) exclusively in Qatar between November 2016 and April 2017. No private hospitals/clinics were covered in Lebanon since none had an outpatient pharmaceutical dispensing outlet. In each area surveyed, a public outpatient health care center was identified, and thereafter, a proximal private sector facility was selected within the same region. The medicine outlets surveyed were contacted and informed of the date, time, and approximate duration of the visit. One facility per sector was covered.

In case of an outlet where less than $50 \%$ of the surveyed medicines were available, a back-up outlet from the same sector was visited where possible. Finding a back-up private community pharmacy in both countries was possible. However, this was not an option in the public sector in Qatar given that only one primary health care center is available per specific area. No validation visits were conducted. For each medicine, data about the originator brand $(\mathrm{OB})$ and the lowest-priced equivalent generic (LPG) available in the outlet at the time of the visit were collected. Each outlet was visited once.

\section{Medicine selection}

To compile a common list of essential CVD medicines, the 2014 Lebanese essential medicine list (EML) available at the time of the study was adopted [35]. This list was in line with the 18th edition of WHO list [35]. To compile a common list, the CVD medicines were first compared to the medicines available in Qatar. As a result, the list of Lebanese CVD essential medicines was refined by excluding the medicines that were not available in Qatar, were not available in level 1 facility, or did not have an international reference price (IRP) as per Fig. 1. The 27 common essential CVD medicines achieved were compared to the latest WHO 19th EML (Table 2). Given that only 22 medicines can be considered for affordability calculation as per the WHO/HAI methodology, only the first line treatment medicines for the main cardiovascular diseases were included in our survey. The decision was made after reviewing the latest cardiovascular disease clinical guidelines [36] and consolidated by a meeting with the clinical pharmacy department in Hamad Medical Corporation (HMC) in Qatar. The final medicine considered for the affordability calculation covered those used for one or more of the following diseases: angina, arrhythmia, hypertension, hyperlipidemia, heart failure, and finally antithrombotic medicines [35]

\section{Outcomes measures}

Unit prices of either tablets or capsules in local currency were recorded. To calculate the median price ratio (MPR), the unit price were converted to US dollar as per Oanda [37] then divided per the IRP collected from International Price Guide (2014) published by Management Sciences for Health (MSH) [38] as per the equation below.

\section{MPR of a specific medicine $=\frac{\text { median local unit price }}{\text { international reference unit price }}$}

Most of the data collection took place between $\mathrm{Au}$ gust-November 2016. As the public primary healthcare centers survey in Qatar was surveyed in 2017, hence the median price ratios for this sector were adjusted based on the corresponding year's consumer price index (CPI) [39]. The median price ratio was calculated if a medicine was found in at least three outlets per sector. An MPR of maximum 4 was considered as a threshold in this study given the costs at different stages along the supply chain. For international comparison of MPR, prices collected in both 




Fig. 1 Refinement process of the surveyed list of medicines

countries were adjusted to purchasing power parity (PPP) as directed in the WHO/HAI manual [9], conversion factors were collected from World Bank [27]. Availability is the percentage of facility where a medicine is stocked out of the total number of facilities per sector. Finally, affordability is expressed in the number of days' wage forgone to purchase the complete treatment of a specific medicine for a month [9]. The daily wages for the lowest paid unskilled government workers (LPGW) were \$20 according to the laws in Qatar and Lebanon [40, 41]. Only medicines that were either first choice for each cardiovascular disease or those that are of national clinical priority were considered for the affordability calculation. The treatment regimen was based on the international standard regimen as per WHO [9] and the new national clinical guidelines launched by the Ministry of Public Health in Qatar [36].

\section{Data analysis}

The Excel workbook available on the HAI website (www.haiweb.org/medicineprices) was utilized for data entry and summary. Daily management and review of collected data were conducted to minimize missing data and errors.

\section{Ethics}

No institutional review board (IRB) approval was required for the study as confirmed by Qatar University. Prior to surveying the "public sector", ethics approval was received from the Primary Health Care Corporation (PHCC) in Qatar and a letter directed to the General Manager of the Ministry of Public Health in Lebanon seeking approval was accepted and signed. As for the private sector, a letter of support from Qatar University was issued and shared with the pharmacy managers prior to the survey in Qatar. In Lebanon, an 
Table 2 List of medicines surveyed

\begin{tabular}{llll}
\hline Medicine name & Dosage strength & Dosage form & Affordability \\
\hline Acetylsalicylic acid & $100 \mathrm{mg}$ & cap/tab & $\checkmark$ \\
Amiodarone & $200 \mathrm{mg}$ & cap/tab & $\checkmark$ \\
Amlodipine & $5 \mathrm{mg}$ & cap/tab & $\checkmark$ \\
Atenolol & $50 \mathrm{mg}$ & cap/tab & \\
Atenolol (2) & $100 \mathrm{mg}$ & cap/tab & \\
Atorvastatin & $10 \mathrm{mg}$ & cap/tab & \\
Atorvastatin (2) & $20 \mathrm{mg}$ & cap/tab & $\checkmark$ \\
Atorvastatin (3) & $40 \mathrm{mg}$ & cap/tab & \\
Bisoprolol & $5 \mathrm{mg}$ & cap/tab & $\checkmark$ \\
Captopril & $25 \mathrm{mg}$ & cap/tab & \\
Captopril (2) & $50 \mathrm{mg}$ & cap/tab & \\
Clopidogrel & $75 \mathrm{mg}$ & cap/tab & $\checkmark$ \\
Digoxin & $0.25 \mathrm{mg}$ & cap/tab & $\checkmark$ \\
Diltiazem & $60 \mathrm{mg}$ & cap/tab & \\
Enalapril & $5 \mathrm{mg}$ & cap/tab & $\checkmark$ \\
Furosemide & $40 \mathrm{mg}$ & cap/tab & $\checkmark$ \\
Gemfibrozil & $600 \mathrm{mg}$ & cap/tab & cap/tab \\
Hydrochlorothiazide & $25 \mathrm{mg}$ & cap/tab & $\checkmark$ \\
Isosorbide dinitrate & $5 \mathrm{mg}$ & cap/tab & \\
Losartan & $50 \mathrm{mg}$ & cap/tab & $\checkmark$ \\
Methyldopa & $250 \mathrm{mg}$ & cap/tab & \\
Propranolol & $10 \mathrm{mg}$ & \\
Propranolol (2) & $40 \mathrm{mg}$ & $10 \mathrm{mg}$ & \\
Simvastatin & $20 \mathrm{mg}$ & \\
Simvastatin (2) & $25 \mathrm{mg}$ & \\
Spironolactone & $80 \mathrm{mg}$ & \\
Verapamil & & & $\checkmark$ \\
\hline
\end{tabular}

endorsement phone call from the local study collaborator was made before the visits.

\section{Results}

Due to the inherent characteristics of the two countries surveyed and limited resources, only two different sectors were surveyed in Lebanon and three in Qatar.

Similarly, the number of facilities visited per sector and per area was limited to one or two upon availability. A total of 30 outlets were visited, 15 per each country.

\section{Prices}

\section{Price variation in local currency}

More price variation incidences were observed in Lebanon than in Qatar of the same medicine type (either OB or LPG) between different outlets within and across sectors. For instance, the MPR of Atorvastatin $20 \mathrm{mg}$
(LPG) in Qatar demonstrated a slight variation between 27.02 and 30.47, while the MPR values of the LPG brands in Lebanon varied between 9.96 the lowest and 18.51 the highest. For this same medicine, the median MPR in Qatar was approximately twice the figure in Lebanon (29.06 vs. 15.34). The price variation of LPG was higher than those of $\mathrm{OB}$ in line with the multitude of generic brands for the same medicine found in the outlets especially in Lebanon. Table 3 demonstrates the few instances of these variations.

\section{Median price ratio (MPR)}

Table 4 illustrates the median MPR for both medicine types across sectors in Qatar and Lebanon. Medicines are free-of-charge in the public sector in Lebanon and only for the Qataris in Qatar. Only the "Public Sector Patient Prices" in Qatar showed acceptable MPR with a median CPI-adjusted MPR of 1.44 (0.452.33 ) and $0.01(0.01-0.01)$ for OBs and LPG, respectively. The LPG CPI-adjusted MPR is not representative of all generics in PHCC since sufficient data was only available to calculate the median MPR of captopril $50 \mathrm{mg}$. The median MPR in the private sector and other sector patient prices were comparable for each medicine type. However, median MPRs for these two sectors were significantly higher than those of a comparative basket purchased from PHCC (Table 5). Purchasing a comparable basket of medicines from community pharmacies or from outpatient pharmacies, patients would have to pay 13.6 and 14.2 times the price paid in PHCC. The median MPR of medicines dispensed in the community pharmacies in Lebanon is $12.37(I Q R=3.30-32.57)$ for $\mathrm{OB}$ and 5.82 $(I Q R=1.85-13.56)$ for LPG, whereas in Qatar it is quite comparable with $21.60(\mathrm{IQR}=6.42-40.43)$ vs. $26.50(\mathrm{IQR}=22.70-29.26)$ for OBs and LPGs respectively (Table 4). It is important to mention that an MPR of more than 5 for the private sector and more than two for public sector is considered as a cut-off values for fairly high prices.

\section{International comparison}

After adjusting for purchasing power parity, the median MPR of medicines (both types) revealed higher price ratio to international reference prices in Qatar than in Lebanon (Table 6). Table 7 demonstrates few examples of purchasing power parity (PPP) and consumer price index (CPI) adjusted-MPR.

\section{Brand premium}

Across all four sectors, the MPR of lowest priced generics were lower than those of their respective originator brands (Table 8). With the near absence of LPG in the public sector in Qatar, the prices of matched LPGs 
Table 3 MPR percentiles variation in the private sectors for both medicine types in Qatar and Lebanon

\begin{tabular}{|c|c|c|c|c|}
\hline Country/sector & Medicine and product type & Median MPR & 25th percentile & 75th percentile \\
\hline \multirow[t]{3}{*}{ Qatar/ Other Sector } & Acetylsalicylic acid- OB & 12.07 & 11.91 & 12.07 \\
\hline & Atorvastatin $20 \mathrm{mg}-\mathrm{OB}$ & 24.11 & 24.11 & 24.11 \\
\hline & Atorvastatin $20 \mathrm{mg}-$ LPG & 29.06 & 27.02 & 30.47 \\
\hline \multirow[t]{3}{*}{ Lebanon/ Private Sector } & Atorvastatin 20 mg- LPG & 15.34 & 9.96 & 18.51 \\
\hline & Hydrochlorothiazide $25 \mathrm{mg}$ - OB & 14.25 & 13.43 & 15.07 \\
\hline & Captopril 50 mg- OB & 3.83 & 3.66 & 3.83 \\
\hline
\end{tabular}

were almost 39 and 34\% lower than their corresponding originators in the two private sectors surveyed. In Lebanon, for the matched pairs of medicines found (13 medicines), the price of LPGs was $65 \%$ less than their respective OBs (Table 8).

As reported per the Qatari and Lebanese pharmaceutical pricing guidelines $[19,20]$, generic medicines should be priced at least 35 and 30\% less than the originator brands in Qatar and Lebanon, respectively. By referring to the brand premium observed in our survey (Table 8), prices of LPG are in line with the regulations in both countries.

\section{Availability}

A high variability in the mean availability of originator brands and lowest priced generics were detected especially in the public primary health centers in both countries (Table 9). The mean availability of generics in Qatar is low with its highest mean (SD) of $29.60 \%$ (37.10\%) observed in the community pharmacies. In the same context, Qatar relies mainly on $\mathrm{OB}$ in its PHCC centers where mean availability (SD) of $\mathrm{OB}$ was $82.20 \%(27.90 \%)$ in the 5 outlets visited with a minimal supply of LPG $5.90 \%$ (15.50\%). PHC in Lebanon are only dispensing generic essential medicines, nevertheless, the availability was critically low with only $46.90 \%$ (36.10\%). The mean availability of $\mathrm{OB}$ and LPG medicines in the community pharmacies in Lebanon was higher than the two private sectors in Qatar. In Lebanon, patients were more likely to face low availability of essential CVD medicines in the public sector in comparison to the private pharmacies.

\section{Affordability}

Affordability was calculated for those medicines available in three or more outlets per sector. Medicines were affordable in the public primary healthcare centers in Qatar (Table 10). While nine out of thirteen medicines were at 1 days' wage or less in all private sector outlets surveyed in both countries, enalapril (antihypertensive medicine), simvastatin and atorvastatin (lipidlowering agents), and clopidogrel (antithrombotic) monthly regimen exceeded the threshold. The originator brand of clopidogrel was the most burdening medicine in both countries as LPGWs have to forgo 4.2 and 2.5 days' wages in Qatar and Lebanon, respectively, in order to purchase their monthly dosage from the private sectors.

For originator brand medicines that impose high burden on LPGW, cheap affordable generics existed. For instance, by substituting originator branded clopidogrel by its generic equivalent, LPGW could have saved 1.6 days' wages in Qatar and Lebanon respectively.

\section{Discussion}

This study was planned to assess the price, availability and affordability of essential cardiovascular medicines within and across Qatar and Lebanon. This study found out that the medicine price was more uniform across the same sector in Qatar than in Lebanon. In the Qatari public sector, medicines were priced lower than the international reference prices. However, the prices of medicines in the private sector were higher than the international reference prices in both countries. The MPR of OBs and LPGs in the private sectors in Qatar (private sector, and other sector surveyed) were up to

Table 4 Median CPI-adjusted MPR of originator and generic brands in all sectors surveyed in Qatar and Lebanon

\begin{tabular}{|c|c|c|c|c|c|c|c|c|}
\hline & \multicolumn{6}{|l|}{ Qatar } & \multirow{2}{*}{\multicolumn{2}{|c|}{$\begin{array}{l}\text { Lebanon } \\
\text { Private }(n=6)\end{array}$}} \\
\hline & \multicolumn{2}{|l|}{ Public $(n=5)$} & \multicolumn{2}{|l|}{ Private $(n=6)$} & \multicolumn{2}{|l|}{ Other $(n=4)$} & & \\
\hline & $\overline{\mathrm{OB}}$ & LPG & $\overline{\mathrm{OB}}$ & LPG & $\overline{\mathrm{OB}}$ & LPG & $\overline{\mathrm{OB}}$ & LPG \\
\hline Median MPR (IQR $\left.{ }^{\mathrm{a}}\right)$ & $1.44(0.45-2.33)$ & $0.01(0.01-0.01)$ & $21.60(6.42-40.43)$ & $26.50(22.70-29.26)$ & $26.71(14.44-46.04)$ & $29.52(25.11-33.81)$ & $12.37(3.30-32.57)$ & $5.82(1.85-13.56)$ \\
\hline Min MPR & 0.09 & 0.01 & 0.72 & 0.40 & 0.72 & 13.28 & 0.52 & 0.32 \\
\hline Max MPR & 9.68 & 0.01 & 67.73 & 44.10 & 67.73 & 44.10 & 59.73 & 41.13 \\
\hline Medicines included & 23 & 1 & 19 & 9 & 14 & 4 & 20 & 17 \\
\hline
\end{tabular}

Note: Min minimum, Max maximum

anterquartile range 
Table 5 Comparison of the median MPR between a common basket of matched pair of medicines across sectors in Qatar

\begin{tabular}{|c|c|c|c|c|c|c|}
\hline & Public & Private & Public & Other & Private & Other \\
\hline Number of matched medicines & 17 & & 14 & & $\begin{array}{l}14(\mathrm{OB}) \\
4(\mathrm{LPG})\end{array}$ & \\
\hline$M P R-O B$ & 1.77 & 24.11 & 1.89 & 26.71 & 26.71 & 26.71 \\
\hline MPR - LPG & & & & & 27.92 & 29.72 \\
\hline$\%$ Difference & $1264.90 \%$ & & $1316.90 \%$ & & $0.00 \% \mathrm{C}$ & \\
\hline
\end{tabular}

two and five times higher than those in Lebanon, respectively. In terms of availability, only the public sector in Qatar met the WHO target for OB CVD medicines. Medicines in the public sector were dispensed free-of-charge for beneficiaries of the National Chronic Drugs Program in Lebanon and for Qatari nationals in Qatar and were all affordable for non-Qataris in the primary health care centers (public sector). In the private sectors surveyed, there were medicines considered unaffordable. In cases where the OB was not affordable, a less expensive generic substitute was available. The higher occurrence of the price variations of the originator brands observed in Lebanon could be due to the fact that the medicine price may change every 2 weeks according to the bi-monthly index released by the MoPH to all warehouses and pharmaceutical outlets. These indices adjust prices based on foreign currency exchange rates fluctuations [17]. Small variations are commonly encountered [42] even under strict pharmaceutical pricing and monitoring regulation as in Saudi Arabia [43], Iran [44] and Lebanon in 2013 [17]. As for LPG' price variations, this could be attributed to the fact that several generic brands of the same active ingredient exist in the market as observed in Saudi Arabia in 2015 [43], Lebanon 2013 [17] and Iran 2014 [44].

The median MPR of OB prices paid by the non-Qatari residents in the public sector were the lowest when compared to those in countries of any income level including Sri Lanka [45], Iran [44], and 11 other Asia Pacific countries [46]. The significant difference in the prices paid by patients between the public and private sectors in Qatar demonstrated the Qatari vision for a subsidized public healthcare system that is of international standard and affordable to all. The high ratios to IRP in community pharmacies in Qatar (21.6 for OB and 26.52 times the IRP for LPG) were also significantly higher when compared to Saudi Arabia (6.66, 8.88 times the IRP) [43] and Iran (3.62, 1.21 times the IRP) [44].

Given that Saudi Arabia and Qatar are utilizing the same pharmaceutical pricing guidelines and bulk procurement for the private sector, the difference in MPR could be related to the higher and linear mark-up schemes applied in Qatar compared to a regressive mark-up in Saudi Arabia. In Lebanon, medicine prices were reduced by the end of 2015, the median MPR of OB increased in 2016 by $2.5 \%$ (12.36 vs. 12.06 times the IRP). This can be due to the fact that the $2013 \mathrm{WHO} /$ HAI survey included a different basket of chronic and acute diseases essential medicines whose prices may have affected the overall median MPR [17]. As for generics, their prices decreased by $18.2 \%$ (5.48 vs. 6.7 times the IRP and close to threshold) after the pricing mechanism of generic medicines was reevaluated, however it is still significantly higher than Iran (1.21 times the IRP) most likely due to more developed domestic generic manufacturing in Iran $[47,48]$.

Accounting for the difference in economic strength $[27,49]$ did not reduce the gap of difference in price observed between Qatar and Lebanon which is in line with other studies that showed the absence of any link between the level of income and the prices of medicines in a country [50-52] except for Schweitzer and Comanor study [53]. The price difference between low-middleincome countries (LMIC) or developing countries on one hand and industrialized countries on the other hand could be due to differential pricing $[54,55]$.

Given that the adjustments to prices applied in this study did not provide possible explanation for the gap in prices between Qatar and Lebanon, further investigation of the landed price ${ }^{2}$ and the pricing mechanisms is needed in the future to provide answers [9].

With the international WHO target to achieve more than $80 \%$ availability of affordable essential generic medicines in at least the public sector by 2030 [1], a slight improvement of the availability of generic essential CVD medicines was observed in the Lebanese public sector in comparison to the year 2013 (46.9\% in 2016 vs. $42 \%$ in 2013). However, this availability is lower compared to the upper-middle income countries (UMIC) average as per Ewen et al. study [1]. This discrepancy may be related to the difference in the medicine basket surveyed.

The absence of OB of essential CVD medicines in the public sector in Lebanon is in line with what Ewen et al. (2017) demonstrated in their secondary study of WHO/

\footnotetext{
${ }^{2}$ Landed price is the second out of five price components. It is the price of a shipped medicine that had cleared customs and import duties, transported to wholesalers or importer. It is the cost of the procurement process.
} 


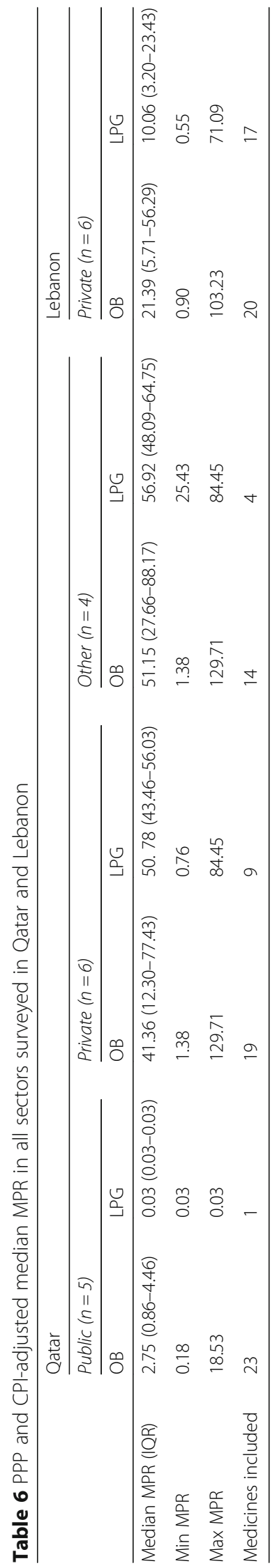


Table 7 PPP and CPI-adjusted MPR of individual medicines in community pharmacy

\begin{tabular}{llllll}
\hline Medicine & \multicolumn{2}{l}{ Qatar } & & & \multicolumn{2}{l}{ Lebanon } \\
\cline { 2 - 3 } & OB & LPG & & OB & LPG \\
\hline Clopidogrel $75 \mathrm{mg}$ & 70.34 & 43.46 & & 37.61 & 13.72 \\
Atorvastatin $20 \mathrm{mg}$ & 89.72 & 48.76 & & 60.75 & 26.52 \\
Amlodipine $5 \mathrm{mg}$ & 129.71 & 84.45 & & 54.55 & 44.37 \\
Acetylsalicylic acid 100 mg & 23.12 & & & 18.15 & 12.94 \\
\hline
\end{tabular}

HAI between 2008 and 2015 for UMICs surveyed in which Lebanon was included alongside Iran, Colombia, Ecuador, Mauritius, Mexico, and Brazil [1].

The subsidy of the public sector in Qatar was also reflected in the predominant availability of originator brands of the surveyed medicines. This availability exceeded the WHO target (82.2\%) [1] and is significantly higher than $\mathrm{OB}$ NCD medicines in the same sector in Saudi Arabia (82.2\% vs. 22.3\%) [43] and the generic medicines availability in the public sector in Iran (75.2\%) [44], where pharmaceutical pricing policies were enacted to control and challenge the OBs entry into the market while generics manufacturing is subsidized and their prices are controlled and competitive $[47,48]$. The low availability of generic medicine in all sectors in Qatar may be related to consumer preferences for OBs [56, 57]. The unavailability of any type of digoxin, diltiazem, amiodarone or isosorbide dinitrate in the private sector may be related to their usage restriction in community pharmacies and to the structure of the healthcare system in Qatar where private cardiology medical services in Qatar are generally limited and mostly available in major hospitals in the capital city.

Our results showed that medicines in the public sector in Qatar were affordable to LPGW. Compared to the private sector in Saudi Arabia, purchasing of medicines by non-nationals in the private sector in Qatar is more affordable when comparing all types of amlodipine and clopidogrel [43]. In Lebanon, despite the fact that the $\mathrm{OB}$ medicines exceeded the one-day' wage threshold in 2016, the few common essential CVD medicines surveyed in Lebanon (clopidogrel, amlodipine, amiodarone, hydrochlorothiazide, simvastatin and atorvastatin) became more affordable in 2016 compared to 2013 [17] and were more affordable than in Saudi Arabia (2015) for any type [43], and more affordable than the OBs in Iran (2014) [44]. Once more, the pharmaceutical pricing policy of OBs in Iran may have resulted in more expensive $\mathrm{OB}$ medicines in comparison to Lebanon.

Nevertheless, the official LPGW salaries adopted for calculation in both Qatar and Lebanon omit a substantial portion of the local population. In Qatar, out of a population of circa 2.58 million, around one million are blue-collar laborers employed in the private sector that are paid almost half of the LPGW salary adopted in our study. In order to calculate affordability for these workers, we would need to almost double the number of days' wages required to purchase a treatment course. Similarly, according to the 2016 UNDP report on Lebanon, 27\% of the population is living under the poverty line and earning less than $\$ 4$ per day [58]. Moreover, as of 2011, there were only 162,016 out of registered beneficiaries under the National Chronic Drug Program in Lebanon who are eligible to obtain free medicines in primary healthcare centers [17]. Overall, roughly half of the Lebanese population has some form of health coverage (public and private) [17], while in Qatar all residents are eligible for subsidized healthcare services and medication through the Primary Health Center Corporation (PHCC) and Hamad Medical Center (HMC). Considering the low availability of medicines in the public sector in Lebanon, most of the patients with chronic diseases are purchasing their medicines from the private sector and thus paying out-of-pocket for CVD medicines. It is worth mentioning that patients with pre-existing conditions or chronic diseases can sometimes find it difficult to obtain private

Table 8 MPR of comparable basket of matched OB and LPG pair medicines found per sector

\begin{tabular}{|c|c|c|c|c|c|c|c|c|c|}
\hline & \multicolumn{6}{|l|}{ Qatar } & \multirow{2}{*}{\multicolumn{3}{|c|}{$\frac{\text { Lebanon }}{\text { Private }}$}} \\
\hline & \multicolumn{3}{|l|}{ Private } & \multicolumn{3}{|l|}{ Other } & & & \\
\hline & $\overline{\mathrm{OB}}$ & LPG & \multirow{2}{*}{$\begin{array}{l}\text { Brand } \\
\text { prem. }\end{array}$} & $\overline{O B}$ & LPG & \multirow{2}{*}{$\begin{array}{l}\text { Brand } \\
\text { prem. }\end{array}$} & $\mathrm{OB}$ & LPG & \multirow{2}{*}{$\begin{array}{l}\text { Brand } \\
\text { prem. }\end{array}$} \\
\hline & 9 & 9 & & 4 & 4 & & 13 & 13 & \\
\hline Median MPR & 43.61 & 26.52 & 1.64 & 45.23 & 29.72 & 1.52 & 21.76 & 7.64 & 2.85 \\
\hline 25\%ile MPR & 36.73 & 22.70 & 1.62 & 38.73 & 25.11 & 1.54 & 4.81 & 2.15 & 2.24 \\
\hline 75\%ile MPR & 48.28 & 29.26 & 1.65 & 52.07 & 33.81 & 1.54 & 35.15 & 15.34 & 2.29 \\
\hline Min MPR & 0.72 & 0.40 & 1.80 & 24.11 & 13.28 & 1.82 & 0.68 & 0.32 & 2.13 \\
\hline Max MPR & 67.73 & 44.10 & 1.54 & 67.73 & 44.10 & 1.54 & 59.73 & 41.13 & 1.45 \\
\hline
\end{tabular}

Note: Min minimum, Max maximum, Prem. premium 
Table 9 Mean availability (in percent) of cardiovascular diseases medicines in sectors surveyed in Qatar and Lebanon

\begin{tabular}{|c|c|c|c|c|c|c|c|c|c|c|}
\hline & \multicolumn{6}{|l|}{ Qatar } & \multicolumn{4}{|c|}{ Lebanon } \\
\hline & \multicolumn{2}{|c|}{ Public $(n=5)$} & \multicolumn{2}{|c|}{ Private $(n=6)$} & \multicolumn{2}{|c|}{ Other $(n=4)$} & \multicolumn{2}{|c|}{ Public $(n=9)$} & \multicolumn{2}{|c|}{ Private $(n=6)$} \\
\hline & $\mathrm{OB}$ & LPG & $\mathrm{OB}$ & LPG & $\mathrm{OB}$ & LPG & $\mathrm{OB}$ & LPG & $\mathrm{OB}$ & LPG \\
\hline Mean Avail. & 82.20 & 5.90 & 64.80 & 29.60 & 54.60 & 25.00 & 0.00 & 46.90 & 69.80 & 58.60 \\
\hline SD & 27.90 & 15.50 & 37.90 & 37.10 & 40.50 & 34.70 & 0.00 & 36.10 & 32.70 & 39.90 \\
\hline
\end{tabular}

Note: Avail. availability, SD standard deviation

insurance as insurers can significantly increase premiums and deductibles or refuse coverage to such patients. It is important to note that most CVD cases require multidrug regimens [2], hence the affordability of a treatment plan would depend on the sum of prices of all drugs prescribed to a patient. The study findings provide several possible policy actions that could be adopted to improve sustainable access to affordable medicines.

Such studies provide valuable advocacy messages for policymakers, pharmaceutical industries, regulators, prescribers and patients if well shared and delivered in a timely manner. Generic uptake in Qatar is still at its infancy, and more effort could be made to promote the acceptance of generic brands among prescribers, pharmacists and patients. Pharmacist should be legally permitted to substitute generic brands for OB. As such, an amendment to the pharmacy practice law enacted in 1980 must be considered. Moreover, facilitating the regulatory process involved in the registration of prequalified quality generic and encouraging the local manufacturing of such medicines are highly recommended. This would result in the optimization of the drug budget in the Qatari public sector by procuring more good quality generic medicines and by providing a cheaper alternative for patients in the private sector.

The price of medicines in the private sector in Qatar must be reconsidered for further price reduction and the linear mark-up added to the supply chain should be replaced by a regressive scheme. Several policy actions could be implemented in Lebanon as well. First, MoPH should prioritize the pharmaceutical budget to ensure that all essential medicines on the national EML are available in the public sector. This can increase the availability of medicines in the public sector and decrease the out-of-pocket spending on pharmaceuticals in the private sector. The coverage of NCD patients under the National Chronic Drugs Program must also be expanded to include the growing segment of the population below the poverty line. The quality of the available generic medicines especially in the private sector in Lebanon should be rigorously assured, and more emphasis should be put into the regulatory

Table 10 Affordability in number of days' wages needed to purchase standard treatment

\begin{tabular}{|c|c|c|c|c|}
\hline & \multicolumn{4}{|c|}{ Days' wages needed to purchase a 30 days' treatment } \\
\hline & \multicolumn{3}{|l|}{ Qatar } & \multirow{2}{*}{$\begin{array}{l}\text { Lebanon } \\
\text { Community pharmacies }\end{array}$} \\
\hline & PHCC & Community pharmacies & Private clinics/hospitals & \\
\hline Bisoprolol $5 \mathrm{mg} \times 60$ & $0.1 \mathrm{OB}$ & $0.9 \mathrm{OB}$ & $0.9 \mathrm{OB}$ & $1 \mathrm{OB} / 0.4 \mathrm{LPG}$ \\
\hline Digoxin $0.25 \mathrm{mg} \times 30$ & $0 \mathrm{OB}$ & & & $0 \mathrm{OB}$ \\
\hline Verapamil $80 \mathrm{mg} \times 90$ & $0.2 \mathrm{OB}$ & & & $1 \mathrm{OB}$ \\
\hline Amiodarone $200 \mathrm{mg} \times 30$ & $0.1 \mathrm{OB}$ & & & $0.3 \mathrm{OB} / 0.2 \mathrm{LPG}$ \\
\hline Amlodipine $5 \mathrm{mg} \times 30$ & $0.1 \mathrm{OB}$ & $0.9 \mathrm{OB} / 0.6 \mathrm{LPG}$ & $0.9 \mathrm{OB} / 0.6 \mathrm{LPG}$ & $0.4 \mathrm{OB} / 0.4 \mathrm{LPG}$ \\
\hline Enalapril $5 \mathrm{mg} \times 120$ & $0.1 \mathrm{OB}$ & $3 \mathrm{OB} / 1.6 \mathrm{LPG}$ & $3 \mathrm{OB}$ & \\
\hline Hydrochlorothiazide $25 \mathrm{mg} \times 30$ & $0 \mathrm{OB}$ & $0.3 \mathrm{OB}$ & $0.3 \mathrm{OB}$ & $0.2 \mathrm{OB}$ \\
\hline Furosemide $40 \mathrm{mg} \times 30$ & $0 O B$ & $0.4 \mathrm{OB}$ & $0.4 \mathrm{OB}$ & $0.4 \mathrm{OB}$ \\
\hline Spironolactone $25 \mathrm{mg} \times 30$ & & $0.4 \mathrm{OB}$ & & $0.2 \mathrm{OB}$ \\
\hline Acetylsalicylic acid $100 \mathrm{mg} \times 30$ & $0 \mathrm{OB}$ & $0.1 \mathrm{OB}$ & $0.1 \mathrm{OB}$ & $0.1 \mathrm{OB} / 0.1 \mathrm{LPG}$ \\
\hline Clopidogrel 75 mg × 30 & $0.4 \mathrm{OB}$ & $4.2 \mathrm{OB} / 2.6 \mathrm{LPG}$ & $4.2 \mathrm{OB}$ & $2.5 \mathrm{OB} / 0.9 \mathrm{LPG}$ \\
\hline Simvastatin $20 \mathrm{mg} \times 30$ & $0.1 \mathrm{OB}$ & $1.4 \mathrm{OB} / 1.1 \mathrm{LPG}$ & & $1.4 \mathrm{OB} / 0.2 \mathrm{LPG}$ \\
\hline Atorvastatin $20 \mathrm{mg} \times 30$ & $0.3 \mathrm{OB}$ & $3.1 \mathrm{OB} / 1.7 \mathrm{LPG}$ & $3.1 \mathrm{OB} / 1.9 \mathrm{LPG}$ & $2.3 \mathrm{OB} / 1 \mathrm{LPG}$ \\
\hline
\end{tabular}


process prior to registration to avoid substandard and counterfeit medicines.

In light of the recent regional blockade on Qatar, it would be relevant to reconduct the survey to measure the efficiency of measures undertaken by local authorities to overcome the situation. More frequent surveys of most common communicable and non-communicable diseases medicines and their price components are needed. The data on medicine price collected in our survey could be used by other methods that measure affordability such as impoverishing and catastrophic effects.

The design of the survey is cross-sectional while in countries where pharmaceutical policies and pricing are amended over time, changes may be better detected by longitudinal studies. Strategic and logistic limitation may have affected the findings. Thus, two limitations arose; a sample size that might have affected the external validity of the study findings and the fact that no quality analysis of medicines was conducted. Furthermore, the affordability may have been overestimated by neglecting the multidrug regimens fact and other healthcare expenses. Finally, including only essential medicines in the surveyed list may have been restrictive especially for the private sector.

To the best of our knowledge, this study is the first in Qatar and the fifth in a high-income country (HIC). Second, the medicines surveyed are of global and national priority and are proven to be safe and cost-effective. Our findings could also be used as indicators for the assessment of millennium development targets and other NCD indicators. Key policy decisions should be implemented to improve access to medicines in both countries.

\section{Conclusion}

By using a variant of the WHO/HAI methodology, we quantitatively evaluated the medicine prices in comparison to international reference prices, as well as their availability and affordability in both Qatar and Lebanon. Pharmaceutical pricing policies were also summarized for comparative purposes. In summary, data revealed that medicine prices were more uniform across the same sector in Qatar than in Lebanon. In general, the price of originator brands and lowest priced generics in Qatar were higher than those in Lebanon. Across all four sectors, the MPR of LPGs were lower than those of their respective OBs. Generally, the studied medicines in the public sector in both countries were either free-of-charge or affordable. In the private sectors surveyed, some medicines were consistently unaffordable. Even in cases where the OB was not affordable, a less expensive generic substitute was available. In terms of availability of medicines, only the public sector in Qatar met the WHO recommendation. In addition, medicines were more available in the private sector in Lebanon than in Qatar. The originator brand availability in the public sector in Qatar exceeded the WHO recommendation. Except for the public sector in Qatar, both countries fall short of the Sustainable Development Goals, and more efforts should be undertaken to achieve these goals.

\section{Appendix}

Abbreviations

CPI: Consumer price index; CVD: Cardiovascular diseases; EML: Essential medicine list; EMRO: Eastern Mediterranean Regional Office of the WHO; HIC: High-income country; HMC: Hamad Medical Center; HMC: Hamad

Table 11 Generic brands pricing strategies in comparison to $O B$ in Qatar

\begin{tabular}{ll}
\hline Qatar & \\
\hline First generic & $\begin{array}{l}-35 \% \text { of the OB price } \\
\text { Second until fourth chronologically } \\
\text { registered generics }\end{array}$ \\
$\begin{array}{ll}-10 \% \text { from the last registered } \\
\text { generic }\end{array}$ \\
$\begin{array}{l}\text { Same price as the fourth } \\
\text { registered generic in the market } \\
\text { or locally packaged generics }\end{array}$ & $\begin{array}{l}\text { Same pricing mechanism as } \\
\text { imported generics }\end{array}$
\end{tabular}

Table 12 Generic brands pricing strategies in comparison to OB in Lebanon

\begin{tabular}{|c|c|c|c|}
\hline \multicolumn{4}{|l|}{ Lebanon } \\
\hline $\begin{array}{l}\text { Generics with } \\
\text { available } O B \text { in } \\
\text { the market }\end{array}$ & $\begin{array}{l}-30 \% \text { of the } \mathrm{OB} \\
\text { price }\end{array}$ & & \\
\hline \multirow[t]{2}{*}{$\begin{array}{l}\text { Generics with } \\
\text { no available } O B \\
\text { in the market }\end{array}$} & Category 1 & $\begin{array}{l}\text { Country of origin: } \\
\text { US, UK, Canada, France, } \\
\text { Austria, Belgium, } \\
\text { Sweden, Germany, } \\
\text { Switzerland, Ireland, } \\
\text { Norway, Denmark, Italy, } \\
\text { Spain, Netherlands, } \\
\text { Finland, Japan, and } \\
\text { Australia }\end{array}$ & \multirow{2}{*}{$\begin{array}{l}\text { Price for the first three } \\
\text { generics in each categor } \\
\text { is set based on Price } \\
\text { Certificate presented at } \\
\text { registration. Within } 3 \\
\text { months of a new generic } \\
\text { being registered, the } \\
\text { price is revised to be the } \\
\text { average price of all } \\
\text { generics within the } \\
\text { category. Price is also } \\
\text { revised in case of price } \\
\text { variation of any of the } \\
\text { generics in the category. }\end{array}$} \\
\hline & Category 2 & All other countries & \\
\hline $\begin{array}{l}\text { Locally } \\
\text { packaged } \\
\text { generics (under } \\
\text { license) }\end{array}$ & $\begin{array}{l}\text { Price depends on } \\
\text { the ex-factory } \\
\text { price in the } \\
\text { country of origin }\end{array}$ & \multirow{2}{*}{\multicolumn{2}{|c|}{ In both cases, price should be $30 \%$ less than OB }} \\
\hline $\begin{array}{l}\text { Locally } \\
\text { manufactured } \\
\text { generics }\end{array}$ & $\begin{array}{l}\text { Price depends on } \\
\text { local ex-factory } \\
\text { price }\end{array}$ & & \\
\hline
\end{tabular}

Medical Corporation; IQR: Interquartile range; IRB: Institutional review board; IRP: International reference price; LMIC: Low-middle-income countries; LPG: Lowest-priced equivalent generic; LPGW: Lowest paid unskilled government workers; MPR: Median price ratio; MSH: Management Sciences for Health; NCD: Non-communicable diseases; NGO: Nongovernmental 
organizations; OB: Originator brand; PHCC: Primary Health Care Corporation; PPP: Purchasing power parity; SD: Standard deviation; UMIC: Upper-middle income country; WHO/HAl: World Health Organization and Health Action International

\section{Acknowledgements}

The authors would like to thank Dr. Yaw Owusu, College of Pharmacy, Qatar University, Doha, Qatar, and Mr. Rabih Hassouneh, Macromed, Beirut, Lebanon for supporting this study.

\section{Authors' contributions}

MIMI and ZUDB supervised NAR in her work. All the authors conceived of the presented idea and designed the study. NAR collected the data and performed the analysis. All the authors involved in the interpretation of data. NAR and MIMI wrote the paper. All authors read and approved the paper.

\section{Funding}

This study was supported by Qatar University with the grants' numbers (QUST-CPH-SPR-15/16-7 \& QUST-CPH-SPR\2017-18). It funded the collection of data and a revision of the written English. The publication fee for this article was funded by the Qatar National Library.

\section{Availability of data and materials}

The datasets generated and/or analysed during the current study are available in the QSpace repository, https://qspace.qu.edu.qa/handle/105 76/11343. It is also available from the corresponding author on reasonable request.

\section{Ethics approval and consent to participate}

No QU IRB approval was required for the study as confirmed by the university. Prior to surveying the "public sector", ethics approval from the concerned entities were collected in both countries. The research study was approved by the Primary Health Care Corporation (PHCC) in Qatar. A letter directed to the General Manager of the Ministry of Public Health in Lebanon seeking approval was accepted and signed. As for the private sector, a letter of support from QU was issued and shared with the pharmacy managers prior to the survey in Qatar. In Lebanon, an endorsement phone call from the local study collaborator was made before the visits.

\section{Consent for publication}

Not applicable.

\section{Competing interests}

The authors declare that they have no competing interests.

\section{Author details}

'College of Pharmacy, Qatar University, PO BOX 2713, Doha, Qatar. ${ }^{2}$ Department of Pharmacy, University of Huddersfield, Queensgate, Huddersfield HD1 3DH, UK

\section{Received: 26 April 2019 Accepted: 10 December 2019}

Published online: 18 December 2019

\section{References}

1. Ewen M, Zweekhorst M, Regeer B, Laing R. Baseline assessment of WHO's target for both availability and affordability of essential medicines to treat non-communicable diseases. PLoS One. 2017;12(2):e0171284.

2. Wirtz VJ, Kaplan WA, Kwan GF, Laing RO. Access to medications for cardiovascular diseases in low- and middle-income countries. Circulation. 2016;133(21):2076-85.

3. Bowry AD, Lewey J, Dugani SB, Choudhry NK. The burden of cardiovascular disease in low- and middle-income countries: epidemiology and management. Can J Cardiol. 2015;31(9):1151-9.

4. World Health Organization (WHO). Health statistics and information system - global burden of disease (GBD). Geneva: World Health Organization; 2012. Available from: http://www.who.int/healthinfo/ global_burden_disease/gbd/en/

5. Mendis S, Abegunde D, Yusuf S, Ebrahim S, Shaper G, Ghannem H, et al. WHO study on Prevention of REcurrences of Myocardial Infarction and StrokE (WHO-PREMISE). Bull World Health Organ. 2005;83(11):820-9.
6. Al-Qasem A, Smith F, Clifford S. Adherence to medication among chronic patients in middle eastern countries: review of studies. East Mediterr Health J. 2011;17(4):356-63.

7. Issam Diab M, Julienne Johnson B, Hudson S. Adherence to clinical guidelines in management of diabetes and prevention of cardiovascular disease in Qatar. Int J Clin Pharm. 2013;35(1):101-12.

8. Frost LJ, Reich MR. Creating access to health technologies in poor countries Health Aff. 2009;28(4):962-73.

9. World Health Organization and Health Action International (WHO; HAl). Measuring medicine prices, availability, affordability and price components. 2nd ed. Geneva: World Health Organization and Health Action International; 2008. Available from: http://www.who.int/medicines/areas/access/OMS_ Medicine_prices.pdf

10. de Joncheere C. Prices, affordability and cost containment. 7th ed. Dukes $M$, Haaijer-Ruskamp F, de Jonecheere C, Rietveld A, editors. Amsterdam: IOP Press; 2003

11. World Health Organization (WHO). Noncommunicable diseases (NCD) country profile. Geneva: World Health Organization; 2014. Available from: http://www.who.int/nmh/countries/qat en.pdf

12. Hobbs FDR. Cardiovascular disease: different strategies for primary and secondary prevention? Heart. 2004:90(10):1217-23.

13. Al-Kaabi SK, Atherton A. Impact of noncommunicable diseases in the State of Qatar. Clinicoecon Outcomes Res. 2015;7:377-85.

14. Deek H, Newton P, Inglis S, Kabbani S, Noureddine S, Macdonald PS, et al. Heart health in Lebanon and considerations for addressing the burden of cardiovascular disease. Collegian. 2015;22(3):333-9.

15. Mohamed Ibrahim MI. Generic medicines policy in Qatar. Gabi. 2015:4(1):8

16. Olayiwola N. Pharmacies sell same medicine at different prices. Gulf Times. 2013. https://www.gulf-times.com/story/340439/Pharmacies-sell-samemedicine-at-different-prices.

17. Health Action International (HAl). Prices, availability, affordability and price components of medicines to treat non-communicable diseases. Lebanon: Health Action International; 2013. Available from: http://haiweb.org/wpcontent/uploads/2015/07/Lebanon-Summary-Report-Pricing-Surveys.pdf

18. Abdel Rida N, Mohamed Ibrahim MI, Babar Z-U-D. Pharmaceutical pricing policies in Qatar and Lebanon: narrative review and document analysis. J Pharm Health Serv Res. 2019;10(3):277-87.

19. Charbel D, Abou Mrad L, Karam R, Raidi C. Pricing drugs guideline in Lebanon Beirut Ministry of Public Health. 1st ed; 2014. Available from: http://www.moph.gov.lb/en/Publications/index/12\#collapse_23

20. Executive Board of The Health Minister's Council for G.C.C States. The rules for pharmaceutical products pricing. 2014. Available from: http://sgh.org.sa/ ar-sa/\%D8\%A7\%D9\%84\%D8\%AA\%D8\%B3\%D8\%AC\%D9\%8A\%D9\%84\%D8\% A7\%D9\%84\%D9\%85\%D8\%B1\%D9\%83\%D8\%B2\%D9\%8A/\%D8\%AA\%D8\% B3\%D8\%B9\%D9\%8A\%D8\%B1\%D8\%A9\%D8\%A7\%D9\%84\%D8\%A3\%D8\%AF\% D9\%88\%D9\%8A\%D8\%A9.aspx.

21. Ministry of Public Health (MoPH). Decision No. 796/1. Beirut: Ministry of Public Health; 2014. Available from: http://www.moph.gov.lb/en/laws\#/ Laws/view/19

22. Docteur E, Paris V, Moise P. Pharmaceutical pricing policies in a global market. France: Organisation for Economic Co-operation and Development: 2008. Available from: http://www.keepeek.com/Digital-Asset-Management/ oecd/social-issues-migration-health/pharmaceutical-pricing-policies-in-aglobal-market_9789264044159-en

23. Cameron A, Hill S, Whyte P. WHO Guideline on country pharmaceutical pricing policies. Geneva: World Health Organization; 2015. Available from: http://apps.who.int/medicinedocs/documents/s21 016en/s21016en.pdf

24. Vogler S, Lepuschütz L, Schneider P. Pharmaceutical distribution remuneration in Europe. JOPPP. 2015;8(Suppl 1):P23.

25. Cameron A, Ewen M, Auton M, Abegunde D. Medicines prices, availability and affordability. Geneva: World Health Organization; 2011. Available from: http://apps.who.int/medicinedocs/documents/s18065 en/s18065en.pdf

26. Business Monitor International (BMI). Lebanon pharmaceuticals \& healthcare report Q3 2016: BMI Research, FitchGroup. 2016. Available from: www. bmiresearch.com.

27. World Bank. Data, Indicators: The World Bank Group. 2016. Available from: http://data.worldbank.org/indicator.

28. Business Monitor International. Qatar pharmaceuticals \& healthcare report Q3 2016: BMI Research, FitchGroup. 2016. Available from: www.bmiresearch.com. 
29. Ministry of Development Planning and Statistics (mdps). Qatar population number: Ministry of Development Planning and Statistics. 2017. Available from: http://www.mdps.gov.qa/en/Pages/default.aspx.

30. Central Intelligence Agency (CIA). The World factbook - Library: Central Intelligency Agency. 2017. Available from: https://www.cia.gov/library/ publications/the-world-factbook/geos/le.html.

31. Snoj J. Population of Qatar by nationality report. 2017. Available from: http://priyadsouza.com/population-of-qatar-by-nationality-in-2017/

32. World Bank. Country and lending groups: The World Bank Group. 2015. Available from: http://data.worldbank.org/about/country-and-lending-groups.

33. Ataullah S. Several medicines become affordable after price cut. The Peninsula; 2016.

34. World Bank. Data, Population density (people per sq. km of land area) The World Bank Group; 2016. Available from: http://data.worldbank.org/ indicator/EN.POP.DNST.

35. Ministry of Public Health (MoPH). List of essential medicines. Beirut: Ministry of Public Health; 2014. Available from: http://www.moph.gov.lb/Drugs/ Documents/EML2014.pdf

36. Ministry of Public Health (MOPH). National clinical guidelines: Ministry of Public Health. 2017. Available from: https:/www.moph.gov.qa/national-clinical-guidelines.

37. Oanda. Currency converter: Oanda Corporation. 2016. Available from: https://www.oanda.com/currency/converter/.

38. Management Sciences for Health (msh). International drug price indicator guide, 2014. Medford: Management Sciences for Health; 2014. Available from: http://erc.msh.org/dmpguide/pdf/DrugPriceGuide_2014.pdf

39. Ministry of Development Planning and Statistics (mdps). Press release on monthly consumer price index (Jan. 2017): Ministry of Development Planning and Statistics. 2017. Available from: http://www.mdps.gov.qa/en/ statistics/Statistical\%20Releases/Economic/Priceindices/CPI/2017/JAN/CPIJAN-2017-AE.pdf.

40. State of Qatar Public Prosecution. Law No. 15 of 2016 promulgating the civil human resources law. Doha: State of Qatar Public Prosecution; 2016. Available from: https://qanoni.pp.gov.qa/legislation/legislation/fd11c5d9cc90-4e4b-b0c4-da04dfeb6ead

41. Ministry of Labor. Decree No. 7426. Beirut: Ministry of Labor; 2012. Available from: http://www.labor.gov.lb/_layouts/MOL_Application/Cur/\%D9\%85\% D8\%B1\%D8\%B3\%D9\%88\%D9\%85\%20\%D8\%AA\%D8\%B9\%D9\%8A\%D9\%8A\% D9\%86\%20\%D8\%A7\%D9\%84\%D8\%AD\%D8\%AF\%20\%D8\%A7\%D9\%84\%D8\% A7\%D8\%AF\%D9\%86\%D9\%89\%20\%D9\%84\%D9\%84\%D8\%A7\%D8\%AC\%D9\% 88\%D8\%B1\%202012.pdf

42. Babar Z, Ibrahim MI, Singh NI, Creese A. Evaluating drug prices, availability, affordability, and price components: implications for access to drugs in Malaysia. PLoS Med. 2007;4(3):e82

43. Health Action International (HAl). Kingdom of Saudi Arabia - Prices, availability, affordability and price components of medicines to treat non-communicable diseases Health Action International. 2015. Available from: http://haiweb.org/ what-we-do/price-availability-affordability/price-availability-data/.

44. Ministry of Health $(\mathrm{MoH})$. Prices, availability, affordability and price components of medicines to treat non-communicable diseases in Iran: Ministry of Health. 2014. Available from: http://haiweb.org/wp-content/ uploads/2015/10/Survey-Iran.pdf. Updated June 2015.

45. Dabare PRL, Wanigatunge $\mathrm{CA}$, Beneragama $\mathrm{BH}$. A national survey on availability, price and affordability of selected essential medicines for non communicable diseases in Sri Lanka. BMC Public Health. 2014;14(1):817.

46. Wang $H$, Sun $Q$, Vitry A, Nquyen TA. Availability, price, and affordability of selected essential medicines for chronic diseases in 11 countries of the Asia Pacific region: a secondary analysis. Asia Pac J Public Health. 2017;29(4):268-77.

47. Zaboli P, Hashemi-Meshkini A, Varmaghani M, Gholami H, Vazirian I, Zekri HS, et al. Pharmaceutical laws and regulations in Iran: an overview. J Res Pharm Pract. 2016:5(3):155-61.

48. Davari M, Walley T, Haycox A. Pharmaceutical policy and market in Iran: past experiences and future challenges. J Pharm Health Serv Res. 2011;2:47-52.

49. Callen T. Purchasing power parity: weights matter: International Monetary Fund. 2012. Available from: http://www.imf.org/external/pubs/ft/fandd/ basics/ppp.htm.

50. Srivastava D, McGuire A. Analysis of prices paid by low-income countries how price sensitive is government demand for medicines? BMC Public Health. 2014;14:767.

51. van Mourik MS, Cameron A, Ewen M, Laing RO. Availability, price and affordability of cardiovascular medicines: a comparison across 36 countries using WHO/HAl data. BMC Cardiovasc Disord. 2010;10:25.
52. Abdel Rida N, Mohamed Ibrahim MI, Babar Z-U-D, Owusu Y. A systematic review of pharmaceutical pricing policies in developing countries. J Pharm Health Serv Res. 2017;8(4):213-26.

53. Schweitzer SO, Comanor WS. Prices of pharmaceuticals in poor countries are much lower than in wealthy countries. Health Aff (Millwood). 2011;30(8): 1553-61.

54. Babar Z, Atif M. Differential pricing of pharmaceuticals: a bibliometric review of the literature. J Pharm Health Serv Res. 2014;5(3):149-56.

55. Danzon PM, Towse A. Differential pricing for pharmaceuticals: reconciling access, R\&D and patents. Int J Health Care Finance Econ. 2003;3(3):183-205.

56. Hassali MA, Alrasheedy AA, McLachlan A, Nguyen TA, Al-Tamimi SK, Ibrahim $\mathrm{Ml}$, et al. The experiences of implementing generic medicine policy in eight countries: a review and recommendations for a successful promotion of generic medicine use. Saudi Pharm J. 2014;22(6):491-503.

57. Kaplan WA, Ritz LS, Vitello M, Wirtz VJ. Policies to promote use of generic medicines in low and middle income countries: a review of published literature, 2000-2010. Health Policy. 2012;106(3):211-24.

58. United Nations Development Programme (UNDP). Rapid poverty assessment in Lebanon for 2016: United Nations Development Programme. 2016. Available from: http://www.lb.undp.org/content/lebanon/en/home/ Response_to_the_Syrian_Crisis/successstories/Rapid-Poverty-Assessment-inLebanon-for-2016.html\#.

\section{Publisher's Note}

Springer Nature remains neutral with regard to jurisdictional claims in published maps and institutional affiliations.
Ready to submit your research? Choose BMC and benefit from:

- fast, convenient online submission

- thorough peer review by experienced researchers in your field

- rapid publication on acceptance

- support for research data, including large and complex data types

- gold Open Access which fosters wider collaboration and increased citations

- maximum visibility for your research: over $100 \mathrm{M}$ website views per year

At $\mathrm{BMC}$, research is always in progress.

Learn more biomedcentral.com/submissions 